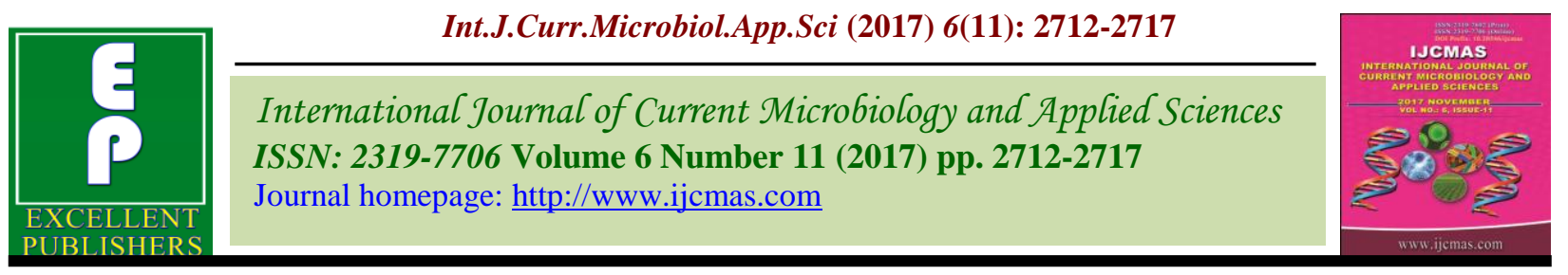

Original Research Article

https://doi.org/10.20546/ijcmas.2017.611.319

\title{
Estimation of Kharif Rice Yield in Khordha District under Future Climate Using DSSAT Model
}

\author{
S. Mohanty ${ }^{1}$, S. Pasupalak ${ }^{1}$, M.K. Beck ${ }^{2^{*}}$ \\ ${ }^{1}$ Department of Agrometeorology, College of Agriculture, OUAT, Bhubaneshwar, India \\ ${ }^{2}$ Department of Agrometeorology, College of Agriculture, IGKV, Raipur-492012, India \\ *Corresponding author
}

\section{A B S T R A C T}

Keywords

Climate change, Rice, CERES model, Yield,

Transplanting dates.

Article Info

Accepted:

20 September 2017

Available Online:

10 November 2017
Odisha is important for cereal crop. In Odisha region the adverse climatic condition is the main cause for lower productivity. Whereas per the different climatic change scenario (RCP 2.6, 4.5, 6.0, and 8.5) at Odisha region for rice crop of variety Khandagiri and Lalat in 2020, 2050 and 2080 projected years. Whereas simulated with the CERES-rice model and found that there is rice yield in both varieties is likely to increase in 2020, almost no change in 2050 and started declining by 2080 except in early and late transplanting dates. In August 1 transplanting, all the varieties performed well whereas their performance was poor in earliest and latest transplanting dates.

\section{Introduction}

Rice is the very important cereal crop of Odisha. But unfortunately productivity of rice crop in Odisha is below the national average. Rice is the major cereal crop of Odisha mainly grown in the kharif season both in irrigated as well rainfed track. Kharif rice area has declined by $10.5 \%$ from 4.336 million hectares in 1970-71 to 3.88 million hectares in 2013-14 whereas, Kharif production increased from 3.913 million tonnes in 197071 to 6.585 million tonnes in 2013-14 due to increase in productivity by $88 \%$ during the period, reaching $1697 \mathrm{~kg} / \mathrm{ha}$ in 2013-14 (Pasupalak, 2016). Adverse climatic condition is the main cause for lower productivity. Further global climate change possesses a high threat to agriculture. Mainly change in weather pattern affects the cropping area and productivity. Rice crop needs a hot and humid climate. It is best suited to regions which have high humidity, prolonged sunshine and an assured supply of water. The average temperature required throughout the life period of the crop ranges from 21 to $37^{\circ} \mathrm{C}$. At the time of tillering, the crop requires a high temperature for growth. The temperature requirement for blooming is in the range of $26.5 \mathrm{oC}$ to $29.5 \mathrm{oC}$ while at the time of ripening the temperature should be in between 20-25oC (De Datta, 1981). Hence, there is a need to study about adverse climatic factors which impact Rice yield under projected 
climate change. Field experiment rice was conducted during kharif 2015 in the Agrometerology field experimental area of OUAT, Bhubaneswar to validate simulated duration to developmental stages and yield with observed experimental data using DSSAT CERES-rice model software. Khandagiri and Lalat were experimental cultivars. Climate change scenarios included weather parameters i.e. temperature, rainfall and solar radiation at Bhubaneswar following RCP 2.6, 4.5, 6.0 and 8.5 scenarios (VanVuuren et al., 2011). Future rice yield projections were made for 2020, 2050 and 2080.

\section{Materials and Methods}

Bhubaneswar is taken as the representative experimental site for Khordha district. The field experiment was carried out at Agricultural meteorology Research farm of College of Agriculture, Orissa University of Agriculture and Technology, Bhubaneswar. It is situated at an elevation of $45 \mathrm{~m}$ above mean sea level at $20015^{\prime} \mathrm{N}$ latitude and $85052^{\prime} \mathrm{E}$ longitude. It comes under East and South Eastern Coastal Plain agroclimatic zone of Odisha, Eastern coastal plain, hot sub humid to semi-arid agroecological region of Odisha and Eastern ghat, hot moist subhumid agroecological sub regions of Odisha.I $t$ also falls under Tropical wet-dry or Tropical Savanna.

Daily weather and soil data of the study area used in study were collected from the Agricultural meteorology Research farm of College of Agriculture, Orissa University of Agriculture and Technology, Bhubaneswar. Genotype (Table 1) and crop management input files were prepared using the available datasets for the specified simulation experiment, and then the CERES- Rice model was run and then used for studying the different scenarios. The field data on growth and development of wheat crop season 201516 were taken from the Department of rice. The growth and development data of rice crop were observed in the field experiment conducted at department of agricultural meteorology, OUAT, Bhubaneswar.

\section{Results and Discussion}

Future scenario of kharif rice yield under projected seasonal climate change for $\mathrm{cv}$. Khandagiri

Projection yield of rice cv. Khandagiri in five transplanting dates under the projected climate RCP 2.6, RCP 4.5, RCP 6.0 and RCP 8.5 scenarios for 2020,2050 and 2080 are given in Table 2 a-e. It also shows the percent of increase or decrease in yield with respect to the present yield. For the year 2020, Model simulated the changes in yield of $+8.1 \%$, $+9.4 \%, \quad+8.2 \%, \quad+8.8 \%$ for July 7 transplanting, $+17.6 \%,+10.7 \%, \quad+17.6 \%$, $+15 \%$ for July 15 transplanting, $+8.6 \%$, $+10.9 \%,+8.6 \%,+10.8 \%$ for August 1 transplanting, $+4.1 \%,+2 \%,+4.1 \%,+5.2 \%$ for August 14 transplanting, $-17.2 \%,+17.1 \%$, $+18.3 \%, \quad+24.1 \%$ for September 8 transplanting under RCP 2.6, 4.5, 6.0 and 8.5 scenarios respectively. For the year 2050, Model simulated the changes in yield of $+2.2 \%,+4.9 \%,+3.8 \%,-0.4 \%$ for July 7 transplanting, $+12.7 \%,+5.5 \%,+5.2 \%,+3.8 \%$ for July 15 transplanting, $+7.4 \%,+2.0 \%$, $+1.6 \%,+2.6 \%$ for August 1 transplanting, $+2.6 \%,+1.5 \%,-3.1 \%,+0.7 \%$ for August 14 transplanting, $+23.7 \%, \quad+19.7 \%, \quad+14.2 \%$, $+15.7 \%$ for September 8 transplanting under RCP 2.6, 4.5, 6.0 and 8.5 scenarios respectively.

For the year 2080, Model simulated the changes in yield of $+2.2 \%,+2.5 \%,+3.7 \%$, $7.3 \%$ for July 7 transplanting, $+12.7 \%$, $+3.2 \%, \quad+4.2 \%, \quad-8.1 \%$ for July 15 transplanting, $+7.4 \%,-1.0 \%,-2.7 \%,-13.5 \%$ 
for August 1 transplanting, $+23.7 \%,+8.2 \%$, $+10.4 \%,-7.3 \%$ for August 14 transplanting, $17.2 \%, \quad+17.1 \%, \quad+18.3 \%, \quad+24.1 \%$ for September 8 transplanting under RCP 2.6, $4.5,6.0$ and 8.5 scenarios respectively. Geethalaksmi et al., (2008), was found rice production declines in Tamil Nadu by 8.7, 23.6 and 42.2 per cent from the production level of the year 2000 in 2020, 2050 and 2080 respectively.

Future scenario of kharif rice yield under projected seasonal climate change for $c v$. Lalat

Projection yield of rice $c v$. Lalat in five transplanting dates under the projected climate RCP 2.6, RCP 4.5, RCP 6.0 and RCP
8.5 scenarios for 2020, 2050 and 2080 are given in Table 3 a-e. It also shows the percent of increase or decrease in yield with respect to the present yield. In general for the year 2020, 2050 and 2080 there is increase in yield under four scenarios for five transplanting dates.

For the year 2020, Model simulated the changes in yield of $+5.0 \%,+5.1 \%,+5.0 \%$, $+3.7 \%$ for July 7 transplanting, $+5.7 \%$, $+3.7 \%,+5.7 \%,+5.3 \%$ for July 15 transplanting, $+10.6 \%,+2.8 \%,+12.8 \%$, $+12.4 \%$ for August 1 transplanting, $+1.2 \%$, +$0.9 \%,+8.0 \%,+6.7 \%$ for August 14 transplanting, $-5.3 \%,+57.6 \%,-2.5 \%,-18 \%$ for September 8 transplanting under RCP 2.6, RCP 4.5, RCP 6.0 and RCP 8.5 projected climate scenarios respectively.

Table.1 Genetic coefficient of different rice varieties

\begin{tabular}{lllllllll}
\hline Cultivers & $\mathbf{P}_{\mathbf{1}}$ & $\mathbf{P}_{\mathbf{2}} \mathbf{R}$ & $\mathbf{P 5}$ & $\mathbf{P 2 0}$ & $\mathbf{G 1}$ & $\mathbf{G 2}$ & $\mathbf{G 3}$ & G4 \\
\hline Khandagiri & 410 & 35 & 290 & 12.5 & 42.0 & 0.0200 & 1 & 1 \\
Lalat & 600 & 80 & 350 & 12.0 & 45.0 & 0.220 & 1 & 1 \\
\hline
\end{tabular}

Table.2 Predicted yield and percent change in yield of cv. Khandagiri in five transplanting dates under four scenarios of climate change for 2020, 2050 and 2080

(a) Transplanting on July 7

\begin{tabular}{|l|l|l|l|l|l|l|}
\hline \multirow{2}{*}{ Scenario } & \multicolumn{2}{|c|}{2020} & \multicolumn{2}{c|}{2050} & \multicolumn{2}{c|}{2080} \\
\cline { 2 - 7 } & Yield & Change (\%) & Yield & Change (\%) & Yield & Change (\%) \\
\hline present & $\mathbf{2 4 1 7}$ & & 2417 & & 2417 & \\
\hline RCP 2.6 & $\mathbf{2 6 1 3}$ & +8.1 & 2469 & +2.2 & 2469 & +2.2 \\
\hline RCP 4.5 & 2645 & +9.4 & 2536 & +4.9 & 2478 & +2.5 \\
\hline RCP 6.0 & 2614 & +8.2 & 2508 & +3.8 & 2507 & +3.7 \\
\hline RCP 8.5 & 2629 & +8.8 & 2407 & -0.4 & 2000 & -17.3 \\
\hline
\end{tabular}

(b) Transplanting on July 15

\begin{tabular}{|l|l|l|l|l|l|l|}
\hline \multirow{2}{*}{ Scenario } & \multicolumn{2}{|c|}{2020} & \multicolumn{2}{c|}{2050} & \multicolumn{2}{c|}{2080} \\
\cline { 2 - 7 } & Yield & Change (\%) & Yield & Change (\%) & Yield & Change (\%) \\
\hline present & 2433 & & 2433 & & 2433 & \\
\hline RCP 2.6 & 2862 & +17.6 & 2743 & +12.7 & 2743 & +12.7 \\
\hline RCP 4.5 & 2693 & +10.7 & 2566 & +5.5 & 2512 & +3.2 \\
\hline RCP 6.0 & 2862 & +17.6 & 2560 & +5.2 & 2544 & +4.6 \\
\hline RCP 8.5 & 2799 & +15.0 & 2526 & +3.8 & 2235 & -8.1 \\
\hline
\end{tabular}


(c) Transplanting on August 1

\begin{tabular}{|l|l|l|l|l|l|l|}
\hline \multirow{2}{*}{ Scenario } & \multicolumn{2}{|c|}{2020} & \multicolumn{2}{c|}{2050} & \multicolumn{2}{c|}{2080} \\
\cline { 2 - 7 } & Yield & Change (\%) & Yield & Change (\%) & Yield & Change (\%) \\
\hline present & $\mathbf{2 3 8 8}$ & & 2388 & & 2388 & \\
\hline RCP 2.6 & $\mathbf{2 5 9 4}$ & $+\mathbf{8 . 6}$ & $\mathbf{2 5 6 5}$ & $+\mathbf{7 . 4}$ & $\mathbf{2 5 6 5}$ & $+\mathbf{7 . 4}$ \\
\hline RCP 4.5 & $\mathbf{2 6 4 8}$ & $+\mathbf{1 0 . 9}$ & $\mathbf{2 4 3 5}$ & $+\mathbf{2 . 0}$ & $\mathbf{2 3 6 5}$ & $\mathbf{- 1 . 0}$ \\
\hline RCP 6.0 & $\mathbf{2 5 9 4}$ & $+\mathbf{8 . 6}$ & $\mathbf{2 4 2 6}$ & +1.6 & $\mathbf{2 3 2 4}$ & $-\mathbf{2 . 7}$ \\
\hline RCP 8.5 & $\mathbf{2 6 4 6}$ & $+\mathbf{1 0 . 8}$ & $\mathbf{2 4 5 0}$ & $+\mathbf{2 . 6}$ & $\mathbf{2 0 6 5}$ & $\mathbf{- 1 3 . 5}$ \\
\hline
\end{tabular}

(d) Transplanting on August 14

\begin{tabular}{|c|c|c|c|c|c|c|}
\hline \multirow[t]{2}{*}{ Scenario } & \multicolumn{2}{|c|}{2020} & \multicolumn{2}{|c|}{2050} & \multicolumn{2}{|c|}{2080} \\
\hline & Yield & Change (\%) & Yield & Change (\%) & Yield & Change (\%) \\
\hline present & 2419 & & 2419 & & 2419 & \\
\hline RCP 2.6 & 2519 & +4.1 & 2481 & +2.6 & 2565 & +2.6 \\
\hline RCP 4.5 & 2467 & +2.0 & 2455 & +1.5 & 2365 & -3.1 \\
\hline RCP 6.0 & 2519 & +4.1 & 2344 & -3.1 & 2324 & -4.0 \\
\hline RCP 8.5 & 2545 & +5.2 & 2435 & +0.7 & 2065 & -25.0 \\
\hline
\end{tabular}

(e) Transplanting on September 8

\begin{tabular}{|l|l|l|l|l|l|l|}
\hline \multirow{2}{*}{ Scenario } & \multicolumn{2}{|c|}{2020} & \multicolumn{2}{c|}{2050} & \multicolumn{2}{c|}{2080} \\
\cline { 2 - 7 } & Yield & Change (\%) & Yield & Change (\%) & Yield & Change (\%) \\
\hline present & 2146 & & 2146 & & 2146 & \\
\hline RCP 2.6 & 1776 & -17.2 & 2655 & +23.7 & 2655 & +23.7 \\
\hline RCP 4.5 & 2513 & +17.1 & 2568 & +19.7 & 2323 & +8.2 \\
\hline RCP 6.0 & 2538 & +18.3 & 2451 & +14.2 & 2369 & +10.4 \\
\hline RCP 8.5 & 2663 & +24.1 & 2482 & +15.7 & 1989 & -7.3 \\
\hline
\end{tabular}

Table.3 Predicted yield and percent change in yield of $c v$. Lalat in five transplanting dates under four scenarios of climate change for 2020, 2050 and 2080

(a) Transplanting on July 7

\begin{tabular}{|l|l|l|l|l|l|l|}
\hline \multirow{2}{*}{ cenario } & \multicolumn{2}{|c|}{2020} & \multicolumn{2}{c|}{2050} & \multicolumn{2}{c|}{200} \\
\cline { 2 - 7 } & Yield & Change (\%) & Yield & Change (\%) & Yield & Change (\%) \\
\hline present & $\mathbf{4 8 4 2}$ & & $\mathbf{4 8 4 2}$ & & $\mathbf{4 8 4 2}$ & \\
\hline RCP 2.6 & $\mathbf{5 0 8 4}$ & $\mathbf{+ 5 . 0}$ & $\mathbf{4 9 3 5}$ & $+\mathbf{+ 1 . 9}$ & $\mathbf{4 9 3 5}$ & $+\mathbf{1 . 9}$ \\
\hline RCP 4.5 & $\mathbf{5 0 9 1}$ & $\mathbf{+ 5 . 1}$ & $\mathbf{4 8 9 5}$ & $+\mathbf{1 . 1}$ & $\mathbf{4 8 1 6}$ & $+\mathbf{0 . 5}$ \\
\hline RCP 6.0 & $\mathbf{5 0 8 4}$ & $\mathbf{+ 5 . 0}$ & $\mathbf{4 8 5 5}$ & $+\mathbf{0 . 3}$ & $\mathbf{4 8 5 8}$ & $+\mathbf{0 . 3}$ \\
\hline RCP 8.5 & $\mathbf{5 0 2 2}$ & $\mathbf{+ 3 . 7}$ & $\mathbf{4 9 2 6}$ & +1.7 & $\mathbf{4 1 0 9}$ & $-\mathbf{1 5 . 1}$ \\
\hline
\end{tabular}

(b) Transplanting on July 15

\begin{tabular}{|l|l|l|l|l|l|l|}
\hline \multirow{2}{*}{ Scenario } & \multicolumn{2}{|c|}{2020} & \multicolumn{2}{c|}{ 2050 } & \multicolumn{2}{c|}{ 2080 } \\
\cline { 2 - 7 } & Yield & Change (\%) & Yield & Change (\%) & Yield & Change (\%) \\
\hline present & $\mathbf{4 9 0 7}$ & & $\mathbf{4 9 0 7}$ & & $\mathbf{4 9 0 7}$ & \\
\hline RCP 2.6 & $\mathbf{5 1 8 7}$ & $+\mathbf{5 . 7}$ & $\mathbf{5 0 8 0}$ & $\mathbf{+ 3 . 5}$ & $\mathbf{5 0 8 0}$ & $+\mathbf{3 . 5}$ \\
\hline RCP 4.5 & $\mathbf{5 0 8 8}$ & $+\mathbf{3 . 7}$ & $\mathbf{5 9 9 5}$ & $\mathbf{+ 1 . 8}$ & $\mathbf{4 9 2 2}$ & $\mathbf{+ 0 . 3}$ \\
\hline RCP 6.0 & $\mathbf{5 1 8 9}$ & $+\mathbf{5 . 7}$ & $\mathbf{4 9 6 2}$ & $\mathbf{+ 1 . 1}$ & $\mathbf{4 9 2 8}$ & $\mathbf{+ 0 . 4}$ \\
\hline RCP 8.5 & $\mathbf{5 1 6 5}$ & $\mathbf{+ 5 . 3}$ & 4948 & $\mathbf{+ 0 . 8}$ & $\mathbf{4 1 1 6}$ & $\mathbf{- 1 6 . 1}$ \\
\hline
\end{tabular}


(c) Transplanting on August 1

\begin{tabular}{|l|l|l|l|l|l|l|}
\hline \multirow{2}{*}{ ccenario } & \multicolumn{2}{|c|}{2020} & \multicolumn{2}{c|}{2050} & \multicolumn{2}{c|}{2080} \\
\cline { 2 - 7 } & Yield & Change (\%) & Yield & Change (\%) & Yield & Change (\%) \\
\hline present & 4218 & & 4218 & & 4218 & \\
\hline RCP 2.6 & 4663 & +10.6 & 4552 & +7.9 & 4552 & +7.9 \\
\hline RCP 4.5 & 4334 & +2.8 & 4431 & +5.0 & 4251 & $+\mathbf{0 . 8}$ \\
\hline RCP 6.0 & 4760 & +12.8 & 4420 & +4.8 & 4336 & +2.8 \\
\hline RCP 8.5 & 4743 & +12.4 & 4397 & +4.2 & 3309 & -21.6 \\
\hline
\end{tabular}

(d) Transplanting on August 14

\begin{tabular}{|l|l|l|l|l|l|l|}
\hline \multirow{2}{*}{ Scenario } & \multicolumn{2}{|c|}{2020} & \multicolumn{2}{c|}{2050} & \multicolumn{2}{c|}{200} \\
\cline { 2 - 7 } & Yield & Change (\%) & Yield & Change (\%) & Yield & Change (\%) \\
\hline present & 3996 & & 3996 & & 3996 & \\
\hline RCP 2.6 & 4045 & +1.2 & 4207 & +5.3 & 4207 & +5.3 \\
\hline RCP 4.5 & $\mathbf{3 9 6 1}$ & -0.9 & 4026 & +0.8 & 3964 & -0.8 \\
\hline RCP 6.0 & 4314 & +8.0 & 3958 & -1.0 & 4091 & +2.4 \\
\hline RCP 8.5 & 4265 & +6.7 & 4249 & +6.3 & 3603 & -9.8 \\
\hline
\end{tabular}

(e) Transplanting on September 8

\begin{tabular}{|l|l|l|l|l|l|l|}
\hline \multirow{2}{*}{ Scenario } & \multicolumn{2}{|c|}{2020} & \multicolumn{2}{c|}{ 2050 } & \multicolumn{2}{c|}{ 2080 } \\
\cline { 2 - 7 } & Yield & Change (\%) & Yield & Change (\%) & Yield & Change (\%) \\
\hline present & $\mathbf{2 3 2 8}$ & & $\mathbf{2 3 2 8}$ & & $\mathbf{2 3 2 8}$ & \\
\hline RCP 2.6 & $\mathbf{2 4 5 2}$ & $\mathbf{+ 5 . 3}$ & $\mathbf{2 2 2 5}$ & $\mathbf{- 4 . 4}$ & $\mathbf{2 2 2 5}$ & $\mathbf{- 4 . 4}$ \\
\hline RCP 4.5 & $\mathbf{3 6 6 9}$ & $\mathbf{+ 5 7 . 6}$ & $\mathbf{3 4 3 4}$ & $\mathbf{+ 4 7 . 5}$ & $\mathbf{3 5 7 2}$ & $+\mathbf{5 3 . 4}$ \\
\hline RCP 6.0 & $\mathbf{2 2 7 0}$ & $\mathbf{- 2 . 5}$ & $\mathbf{3 2 4 6}$ & $\mathbf{+ 3 9 . 4}$ & $\mathbf{3 2 0 1}$ & $+\mathbf{3 7 . 5}$ \\
\hline RCP 8.5 & $\mathbf{1 9 0 0}$ & $\mathbf{- 1 8 . 4}$ & $\mathbf{1 9 0 0}$ & $\mathbf{- 1 8 . 4}$ & $\mathbf{3 4 8 6}$ & $+\mathbf{4 9 . 7}$ \\
\hline
\end{tabular}

For the year 2050, Model simulated the changes in yield of $+1.9 \%,+1.3 \%,+0.3 \%$, $+1.7 \%$ for July 7 transplanting, $+3.5 \%$, $+1.8 \%, \quad+1.1 \%, \quad+0.8 \%$ for July 15 transplanting, $+7.9 \%,+5.0 \%,+4.8 \%,+4.2 \%$ for August 1 transplanting, $+5.3 \%$, $+0.8 \%$, $1.0 \%,+6.3 \%$ for August 14 transplanting, $4.4 \%, \quad+47.5 \%, \quad+39.4 \%, \quad-18.4 \%$ for September 8 transplanting under RCP 2.6, RCP 4.5, RCP 6.0 and RCP 8.5 projected climate scenarios respectively.

For the year 2080, Model simulated the changes in yield of $+1.9 \%,-0.5 \%,+0.3 \%$, $15.1 \%$ for July 7 transplanting, $+3.5 \%$, $+0.3 \%, \quad+0.4 \%,-16.1 \%$ for July 15 transplanting, $+7.9 \%,+0.8 \%,+2.8 \%,-21.6 \%$ for August 1 transplanting, $+5.3 \%,-0.8 \%$, $+2.4 \%,-9.8 \%$ for August 14 transplanting, $4.4 \%, \quad+53.4 \%, \quad+37.5 \%, \quad+49.7 \%$ for September 8 transplanting under RCP 2.6,
RCP 4.5, RCP 6.0 and RCP 8.5 projected climate scenarios respectively. Naresh Kumar et al., (2011) also found similar results as he predicted a marginal increase of less than 5\% in irrigated rice yields in some coastal districts of Orissa, by 2030. Similar findings are also obtained by Mohapatra and Kar (1991), who reported that mean grain yield of CR-1009 variety of rice were 3.88,3.82,3.63,AND 3.43T ha $^{-1}$ when transplanted on 16 July, 31 July, 15 August, and 30 August.

For Khandagiri, in 2020, there is a marked increase in yield under four scenarios but in 2050, almost no change in yield occurs except for the latest transplanting date where yield increases. In 2080, yield increases under early and late transplanting dates whereas declines under midseason transplanting dates. RCP 8.5 scenario results in declining yield in all 
transplanting dates in 2080. For Lalat, in 2020, there is a marked increase in yield under four scenarios but in 2050, almost no change in yield occurs except for the latest transplanting date. In 2080, RCP 8.5 scenario results in declining yield in all transplanting dates except for latest transplanting. However, in other RCP scenarios there is almost no change in yield except for latest transplanting where there is a marked increase in yield. Rice yield in both variety is likely to increase in 2020, almost no change in 2050 and started declining by 2080 except in early and late transplanting dates. In August 1 transplanting, all the varieties performed well whereas their performance was poor in earliest and latest transplanting dates.

\section{References}

Aggarwal PK and Mall RK.2002. Climate change and rice yields in diverse agroenvironments of India. II. Effect of uncertainties in scenarios and crop models on impact assessment, Climatic Change, 52(3):331-343.

Begum AA, Altaf Hossain SM and Moin-us S. 2000. Growth duration, temperature sum, photoperiod and yield of rice as influenced by date of transplanting. Bangladesh Journal of Agricultural Science, 27(2):191-197.

De Datta SK, Faya FG and Seshu DV. Soilwater relations in upland rice. Proceedings of soil management in tropical America, CIAT, Cali, Columbia, USA. 1975. 168-185.

Geethalaksmi V, Kokilavani S, Nagarajan R, Babu C and Poornima S.2008.Impacts of climate change on rice and ascertaining adaptation opportunities for Tamil Nadu, Journal of Agrometeorology, special issue (2):282285.

Hundal SS, Kaur P and Dhaliwal LK. 1998. Prediction of potential productivity of rice in Punjab, India under synthetic climatic change scenarios. Pp 172-1787, In: Modelling for Crop- Climate-SoilPest system and its Applications in Sustainable Crop Production. 22-26 June 1998, Nanjing, China. Jiangsu Academy of Agricultural Sciences publisher, Nanjing, China.

Mohapatra AK and Kar PC.1991. Effect of time of planting age of seedling and level of $\mathrm{N}$ on yield and $\mathrm{N}$ - uptake of lowland rice, Orissa Journal Agricultural Research, 4 (1-2):23-26.

Om H, Singh OP and Joon RK. 1993. Effect of time of transplanting and spacing on Basmati rice, Haryana Journal Agronomy, 9(1):87.

Pasupalak S. 2016. Agroclimatic Atlas of Odisha. AICRP on Agrometeorology, OUAT, Bhubaneswar - 751003 .

Paul SR.1993. Effect of age of seedlings and dates of transplanting on grain yield of sail rice in Assam, Annals of Agricultural Research, 15(1):126-128.

Saseendran SA, Singh KK., Rathore LS, Singh SV and Sinha SK.2000. Effects of climate change on rice production in the tropical humid climate of Kerala, India, Climatic Change. 44(4):495-514.

VanVuuren DP. 2011. The Representative Concentration Pathways: an overview. Climate Change, 109:5-31.

\section{How to cite this article:}

Mohanty, S., S. Pasupalak, Beck, M.K. 2017. Estimation of Kharif Rice Yield in Khordha District under Future Climate Using DSSAT Model. Int.J.Curr.Microbiol.App.Sci. 6(11): 27122717. doi: https://doi.org/10.20546/ijcmas.2017.611.319 